\section{Intuitive Development of the Concept of Integers among Primary School Students}

\author{
Cemre Cengiz ${ }^{\mathrm{a},}{ }^{*}$, Ebru Aylar ${ }^{\mathrm{b}}$, Esengül Yıldız
}

$\begin{array}{ll}\text { Received: } & 19 \text { September } 2018 \\ \text { Revised: } & \text { 03 October } 2018 \\ \text { Accepted: } & 10 \text { December } 2018 \\ \text { ISSN: } 1307-9298 \\ \text { Copyright (C) IEJEE } \\ \text { www.iejee.com }\end{array}$

DOI: 10.26822/iejee.2019248599

\begin{abstract}
This paper investigated the intuitive development of the concept of integers among primary school students. In order to reveal if primary school students had an intuitive sense of integers, an assessment consisting of five questions was prepared and applied to a total $1004^{\text {th }}$ grade students. A variety of integer concepts were utilized in the assessment including; integer ordering, less-than greater-than relations, as well as, integer addition and subtraction. In order to analyse the assessment data a coding system was utilized. Two researchers separately coded the students' answer responses, and later met with a third researcher to resolve any differences of rater reliability. According to the findings from this research, the $4^{\text {th }}$ grade students investigated did exhibit an intuitive understanding of integers. In order to build upon students understanding of integers, examples from daily life as well as cardinal and ordinal meanings of numbers should be utilized in future instruction.
\end{abstract}

Keywords: Integers, Intuitive Understanding, Cardinal Understanding, Ordinal Understanding, Children's Thinking

\section{Introduction}

Learning begins early in life and even before the beginning of a child's formal education the concepts of numbers, counting, and relations such as more/less develop naturally through their daily life experience. In other words, daily life experiences are the basis for our intuitive learning, for example, we are exposed to the intuitive concept of negative numbers through the negative temperatures listed on a thermometer, as well as, being aware of the negative number of floors in a building. Children can perceive that the temperature of -10 degrees Celsius is colder than the temperature of 10 degrees. Furthermore, understanding that owing 10 Turkish liras to the school canteen is more debt than not owing anything. Taking an elevator with their family can also allow young children to recognize the difference between the positive and negative numbers of floors at a shopping mall. As a result, it is clear that people are exposed to negative numbers on a daily basis through a variety of concepts. Unfortunately, transforming intuitive understanding from real life experiences into formal mathematical learning can be a challenge for both educators and learners.

Past research has shown that students can have difficulty with the subject of negative numbers (Altıparmak \& Özdoğan, 2005; Kilpatrick, Swafford \& Findell, 2001; Beswick, 2011; Whitacre, Bishop, Lamp, Philipp, Schappelle \& Lewis, 2012a; Vlassis, 2008). During the learning process of negative numbers, students may encounter a number of difficulties ranging from the construction of the concept of negative numbers (Ball, 1993; Fischbein, 1987), to understanding the four operations of integers (Altun, 2008; Crowley \& Dunn, 1985; Van de Walle, Karp \& Williams, 2007). When the concept of negative numbers is first presented to students it may seem abstract to them, and as a result, create conflict with their prior knowledge regarding natural numbers and mathematical operations for natural numbers. In other words, certain features relating to negative numbers can conflict with the man- ner in which students perceive counting numbers (Linchevski \& Williams, 1999). As a result, because of the conflict that students may experience with the concept of integers, they revert to memorizing basic rules instead of actually acquiring the conceptual knowledge.

In formal education at schools children acquire knowledge regarding the cardinal and ordinal nature of numbers. Developing this knowledge is important for students because understanding the cardinal principle (e.g., cardinality) is necessary when learning the set of natural numbers. Gelman and Gallistel (1986), explain the principle of cardinality as the association of a quantity of objects to the last number from the counting sequence. While according to Bishop, Lamb, Philipp, Whitacre, and Schappelle (2014), ordinality is understood as the concept of ordering which means to perceive a set of integers not by quantity but by their sequential or positional relations (e.g., -3 is greater than -4 and less than -2). Also important, is that the principles of cardinality and ordinality are developed together; otherwise, there may be a risk that numbers are only comprehended as a quantity of a group of objects which may lead to difficulties for learners to perceive a set of integers (Fischbein, 1987; Otten, 2009). For example, at first it can be difficult for learners to accept that there can be a value (e.g., number) less than zero. Many students may be confused and only consider zero as "nothingness", and as a result, struggle with grasping the concept of negative numbers. At this point the importance combining an understanding of cardinality and ordinality becomes clearer because for some students it may be difficult to discard the idea of "nothingness" of zero based solely on the cardinal relation, yet instead working backwards from zero (e.g., the starting point) with an ordinal approach can lead to an easier understanding of this concept.

When we reviewed the relevant research studies regarding the teaching of integers, it was recognized that both cardinality and ordinality are effective strategies in the teaching 
of integers. For example, when reviewing particular studies from the literature it was determined that zero and negative numbers can be understood through ordinal values by using a number line (Bescwick, 2011; Carson \& Day, 1995; Hativa \& Cohen, 1995). In another example, it was determined that the conceptualization of negative numbers with the cardinal value approach was understood through the use of situations and encounters from daily life (Behrend \& Mohs, 2006; Goldin \& Shteingold, 2001). The success of teaching integers via both the cardinal and ordinal approach has created an argument for which model is the most effective integer instruction strategy, and as a result, a multitude of studies have been carried out to research this topic. A 1989 publication from the National Council of Teachers of Mathematics (NCTM) (1989) emphasized the use of the number line teaching strategy is more effective for teaching integers in the $5^{\text {th }}$ to $8^{\text {th }}$ grades. Although use of a number line teaching approach has gained importance because of its emphasis in the NCTM (1989), the cardinal and ordinal principles and the models related to these principles, should be taken together when constructing conceptual learning regarding integers as well as for other sets of numbers.

Throughout the world and in Turkey the teaching of integers in schools usually begins at the middle school level. Despite the widespread acceptance of starting integer instruction during middle school, there remains a controversy of when is the appropriate time to begin teaching integers. As of 2017 though, curriculum changes in Turkey established the teaching of integers to begin in the $6^{\text {th }}$ grade. Along with introducing the concept of integers at the $6^{\text {th }}$ grade level, the comparison and ordering of integers, is also included in the curriculum. In addition, following the introduction of integers in the $6^{\text {th }}$ grade, the topic of operations with integers is introduced at the $7^{\text {th }}$ grade level (Milli Eğitim Bakanlığı (Ministry of National Education), 2017). In the past, the concept of integers was first instructed in the $6^{\text {th }}$ grade as well as the addition and subtraction of integers was also instructed at this level. Again, the more complex instruction of multiplication and division of integers was understandably left for the $7^{\text {th }}$ grade level of instruction and took place as part of the "Numbers and Operations" instruction (Milli Eğitim Bakanlığı, 2013). The understanding was that the complex nature of integer instruction is better left to be instructed during the latter part of secondary school.

Throughout much of the world today as well as in Turkey the teaching of integers begins at the secondary school level even though some believe that integer instruction should begin at an earlier stage of mathematics education. The argument to begin integer instruction at an earlier age is often based on the idea that young children do have an intuitive understanding of integers, and as a result, the formal teaching or at least introduction of integers should begin during primary school (Cathcart, Pothier, Vance, \& Bezuk, 2003; Galbraith, 1974; Goldin \& Shteingold, 2001; Hativa \& Cohen, 1995; Murray, 1985; Streefland, 1996). Another publication by the National Council of Teachers of Mathematics (NCTM, $2000)$, stated that students as early as the $3^{\text {rd }}$ to $5^{\text {th }}$ grades can begin to perceive numbers smaller than zero by extending the number line and/or by using similar forms of applications and instruction. Umay and Akkuş emphasized in a workshop report related on the evaluation of Primary-Secondary School Curriculums and Course Books published in 2008, that students should meet with the concept of "negative" in primary school, and the subject of operations in integers can start at the $6^{\text {th }}$ level (as cited in Işıksal-Bostan, 2009). Furthermore, past research studies regarding the concept of integers among young children have revealed that students can develop an understanding of negative numbers as well as perform addition and subtraction at a basic level in primary school.
When examining past studies regarding the concept of integers it was recognized that a variety of researchers had carried out experiments to better understand the appropriate age for introducing and/or instructing young students about this concept. For example, Wilcox (2008), carried out an experiment with his daughter who was a $1^{\text {st }}$ grade student by playing a game utilizing a number line which had zero and only positive numbers but the negative numbers were not listed except for the places where the numbers should be written. Wilcox's game also included game cards with negative or positive numbers written on them, and after selecting a card each player was supposed to start at zero on the number line and then go the specified number of places up (e.g., positive numbers) or down (e.g., negative numbers) the number line. During the game when the daughter first selected a negative numbered card (e.g., the -3 card) Wilcox observed how she reacted, and through discussion with her, she seemed to become aware of the existence of negative numbers as well as how to proceed. Although, the daughter was initially hesitant on how to proceed to the left of zero, she ultimately selected the point three spaces to the left of zero and coined this position "zero cousin -3 spot". As a result, the young girl identified negative numbers as "cousins" to the positive numbers. It appears she had discovered negative numbers by first attributing ordinal value to them, which was associated with the concept of "borrowing" in later parts of the game through an understanding of cardinal value.

In another study, Bishop et al. (2014), conducted a case study involving the use of integers for addition and subtraction with a $2^{\text {nd }}$ grade student, Violet, who had not previously been introduced and/or instructed regarding the concept of negative numbers. As a result of this study, it was recognized that students can develop an intuitive understanding of negative numbers before actually receiving formal instruction about them, and it was also emphasized that reasoning solely based on ordering (e.g., ordinality) can be an effective method of understanding negative numbers as well as the operation of integers. To continue, Behrend \& Mohs (2006), conducted research over a two year period with 20 first graders, where the students were instructed about the concept of negative numbers as well as about addition and subtraction accompanied by problem setting and solving activities. The study began by discussing these questions; "Do the numbers ever stop?" and "Do the numbers stop if we count backwards?" which introduced the students to the concept of negative numbers. Following the students' introduction to the concept of negative numbers, then the students were asked to complete activities and problems by using negative numbers for addition and subtraction. The research results indicated that in problem solving situations, the use of discussion regarding the presented problem, can be an effective and useful approach for developing better understanding about a topic. Finally, Whitacre et al., (2012a) conducted a study with three students, each in the $1^{\text {st }}, 3^{\text {rd }}$ and $5^{\text {th }}$ grade respectively, in order to examine the perceptions of primary school students regarding the basis of their concept of integers. In their research, they addressed the abstraction contained in the concept of integers by introducing the opposing states of being happy or sad. By introducing this abstraction, the researchers observed an increase in the $1^{\text {st }}$ to $5^{\text {th }}$ grade students understanding of the use of both positive and negative numbers.

\section{Purpose and Significance of the Research}

The studies of integers with young children reveals that the intuitive understanding developed by students through experiences in their daily life is an effective manner of creating an understanding of the concept of integers as well as performing basic addition and subtraction operations. On the other hand, past research has also shown that the 
initial learning of natural numbers in primary school ultimately has a negative effect on the instruction of integers (Fischbein, 1987; Linchevski \& Williams, 1999). This presents two different situations; on the one hand the instruction of negative numbers can be started in primary school by taking advantage of the intuitive understanding of students, while on the other hand the fact that the integer instruction can be taken farther in the later grades may be a better approach. The concern related to starting the instruction of integers in the earlier years of primary school is involved with students experiencing difficulties when learning about integers in later grades. Furthermore, it unfortunately appears that the educational instruction in today's primary schools has not been able to effectively create a readiness for the instruction of the concept of integers.

It is possible that during their primary school years young children can develop an intuitive understanding of numbers and integers through their encounters with the surrounding environment as well as through counting numbers. In addition, primary school children can also gain a basic concept of rational numbers through their exposure to the concept of fractions. Most often the mathematical knowledge regarding the existence of numbers less than zero (e.g., negative numbers) is not taken into consideration until the $6^{\text {th }}$ grade, and as a result, during primary school education this information has been left incomplete regardless of if the children can intuitively understand the concept or not. The risk of not presenting the concept of negative numbers to primary school students is that they may ultimately develop the perception that "there is no number less than 0 " and this perception can create a faulty generalization that, "the big number is not subtracted from the small number". Future misconceptions among learners can occur if their intuitive understanding of mathematical concepts is not parlayed from their primary school instruction into the more complex instruction that occurs in the higher grades of middle school. When young children do not fully grasp the concept of negative numbers due to the instruction they received during primary school they may have more difficulty grasping the concept during their later mathematical instruction. As a result, the consideration of when to introduce and fully instruct students regarding more complex mathematical concepts, such as, integers and negative numbers should be not taken lightly and instead well researched, tested, and determined through these measures. When structured research regarding this topic is carried out, not only can assessments, experiments, and observations be utilized to better understand the best approach of where and when the concept of negative numbers and integers be instructed to students, but also; academics, educators, and researchers can be more aware of how to utilize students' intuitive understanding of these concepts before providing the more complex instruction. This is important because a better and more complete understanding of students' methods of intuitive learning and understanding can provide important and useful data regarding the appropriate period for integer instruction as well as what content and information it should include.

There has been a significant amount of research conducted in Turkey regarding integers but for the most part this past research has focused mainly on the secondary school level and has done little to address these questions for education at the primary school level. As a result, this research was focused on attempting to better understand primary school students' intuitive development of the concept of integers and negative numbers. Does children's intuitive learning developed through their own experiences involve the concept of integers as well as the basic addition and subtraction skills of integers? Specifically, this research aimed at revealing $4^{\text {th }}$ graders intuitive understanding of the concept of integers, as well as, determining how the research findings can contribute to the argument for introducing and instructing the concept of integers at the primary school level.

\section{Method}

This research was qualitative in nature and aimed to investigate primary school students' intuitive understanding of the concept of integers. In order to carry out this research investigation the following form of research methodology was utilized including the participants, procedure, and data analysis type described below.

\section{Participants}

This study was conducted in a primary school located in the Çankaya district of Ankara, Turkey and took place during the 2016-17 academic school year. The research was carried out with a total of 104 participant students from four differing $4^{\text {th }}$ grade classrooms. In accordance with the qualitative nature of this study, non-probability sampling was effective in determining if the school, classrooms, and students were appropriate to participate in this study. Also, as Kümbetoğlu (2005) pointed out, since qualitative research seeks to examine social reality then it is important not to just gain generalizations through representative samples but instead to choose a sample from which to compile data.

An attempt was made through purposive sampling to select a typical case sample by choosing a school with participants from the middle socio-economic class rather than one from the upper and/or lower socio-economic classes. In a typical case sample, according to Büyüköztürk, Çakmak Kılıç, Akgün, Karadeniz, and Demirel (2012), the sample is formed by choosing a typical sample from among the target population based on the specific purpose and problem associated with the research. To have a typical sample for this research, a school which was considered a relatively representative sample was selected within the research city.

To begin the data collection process of this study, a total of 104 students were provided an assessment consisting of five questions, and following review of the students assessment responses a study group of 100 students was identified. Next, according to the students' responses, a group of 11 students viewed as representative of the best assessment responses, were selected for in-depth semi-structured interviews. These semi-structured interviews were conducted in order to more precisely clarify the motivation behind students' answer responses.

\section{Procedure}

As mentioned previously, in order to investigate the students' intuitive understanding relating to integers, an assessment consisting of five questions was carried out. The assessment was made up of questions relating to ordering, less than-greater than relations, as well as, basic addition and subtraction of integers.

Initially, the assessment questions were prepared by the researchers, and then experts were consulted regarding their opinions of the prepared questions, and the final version of the questions were prepared according to the experts feedback. Next, in order to evaluate the clarity of the assessment questions, the assessment was applied to a group of similar age students in order to gain their opinions regarding the language structure and contents of the questions.

The assessment utilized in this research was compiled of five questions; the first question was the addition of a negative and positive number, and the question resembled that used by Whitacre et al., (2012a), where the opposites of 
happy and sad were used to demonstrate the difference between positive and negative numbers. The second question involved the addition of two negative numbers by use of the borrowing framework. In these questions, first the students were provided with a question related to a situation from daily life, and then in Part A of the question the students were asked to answer by using numbers and operations. For Part B, three different operations were provided to students and they were asked which operation given was the result to the question. This is important because in the first part of the question students were expected to use their own imagination when answering, and for the second part of the question the goal was to determine if students chose the correct operation to answer the question.

The third question was the subtraction of a negative number from a positive number, and the question presented the scenario of an elevator descending and having negative numbered floors. For question three the students were asked to answer the question directly.

For the fourth question the students were presented with five different integer pairs and asked to indicate which the greater number in these pairs was. At fifth question, a visual aid was provided to the participants by way of a number line. On the number line though only the numbers +2 and +3 were listed, and as part of the question the students were asked to fill out the number line correctly (e.g., positive \& negative numbers).

After the participants had completed the study, an in-depth semi-structured interview was prepared in order to better understand the students' motivation for their answers to the questions. Following the preparation of the semi-structured interview 11 students were selected to be interviewed indepth regarding their answers.

\section{Data Analysis}

During the analysis of the collected data, a separate code was developed for each question, and two researchers coded the data separately. The coding results of the researchers were compared and the coding consistency percentage was determined to be $98 \%$.

For the interview and coding process the interviews were first conducted, then transcribed, and finally coded separately by two researchers. The data gathered from both the assessment and interview questions were reported under these themes; "addition of integers", "subtraction of integers", "less-than, greater-than relations", and "ordering". In order to maintain the anonymity of the study participants their real names were not used in the study and instead pseudonyms were given for each student according to their gender.

\section{Results and Discussion}

The research findings from the analysis of the data collected in this study were all listed under the themes, "addition of integers", "subtraction of integers", "less-than, greater-than relations", and "ordering".

\section{Addition of integers}

The first two questions of the assessment involved the addition of integers. In the first question (question 1), the students were presented with the following question scenario.

"Ayşe has happy and sad thoughts every day. If Ayşe has 1 happy thought and 1 sad thought, then she feels normal that day, in other words Ayşe does not feel happy nor sad that day. If Ayşe has 2 happy thoughts and 7 sad thoughts on Monday, how does she feel on Monday?"
The researchers presented this scenario to the students in order to investigate how they would understand opposing situations; in particular, would the students associate the opposite situations in the question with negative-positive numbers. In the second question (question 2) the researchers presented the students with a question related to the idea of borrowing in order to examine

"You borrowed 8 Turkish liras for lunch from a friend yesterday. Today you have borrowed 5 more Turkish liras for breakfast from the same friend."

The borrowing scenario question was presented to students in order to investigate their ability to associate negative numbers with borrowing. The coding system utilized in the analysis of parts $A$ and $B$ for the first two questions (question 1 \& question 2) are presented by the following codes. Also, the findings from question 1 are presented in Table 1.

Code 1: Correct answers achieved by using negative-positive numbers

Code 2: Correct answers reached without using negative numbers

Code 3: No answer or unrelated answers

Table 1. The findings related to question 1

\begin{tabular}{lcc}
\hline & Part A & Part B \\
\hline Code 1 & 9 & 26 \\
\hline Code 2 & 60 & 63 \\
\hline Code 3 & 31 & 11 \\
\hline
\end{tabular}

Reviewing the analysis of question 1 it was revealed that in Part A, a majority of the students $(n=60)$ answers, were related to Code 2. These students answered, "Sad for 5 times", which utilized the operation $7-2=5$ and as a result arrived at the correct answer through the use of positive numbers. The responses to the same question from another nine students were more closely related to Code 1 by expressing their answer as $-7+2=-5$. This group of nine students were able to express their answer by using their intuition as it related to negative numbers. This number increased to 26 in Part B of question 1 when mathematical expressions were provided to the students in order to aid them in choosing the correct operation. The 26 students from Part B stated that the operation for the question was $(+2)+(-7)=-5$, but the majority of students ( $n=63$ ) continued to choose the operation $7-2=5$, and another 11 of the students chose $(-7)-$ $(-2)=-5$ which was an incorrect answer and not related to the question. Reviewing the responses provided by the students it can be stated that the tendency of most students was to reach their conclusion by considering natural numbers, yet even though this was the case it was also clear that there were students who could utilize negative numbers in their solution. Importantly, it was also recognized that some students whose answer was related to Code 2 for Part A having preferred to use negative numbers had an answer related to Code 1 for Part B of the question.

One student in particular who chose Code 2 for Part A was, Ahu. In explaining her response, Ahu, created a fictional statement regarding natural numbers.

"Because she is sad 7 times but she is happy 2 times. So 1 happy can eliminate $1 \mathrm{sad}$. That's why I subtracted 2 from 7. So $5 \mathrm{sad}$ faces remain. If you ask which one is bigger among 5 and 2, the answer is 5. So she is sad."

The student, Ahu, further explained her answer for Part B by stating; $(+2)+(-7)=-5$, and in particular when using negative numbers, "For example, plus can represent happy, and minus can be sad". 
b) Bu durumu sayısal olarak yani sayılar ve dört işlem işaretlerini kullanarak, bir esitlike ifade edebilir misin?

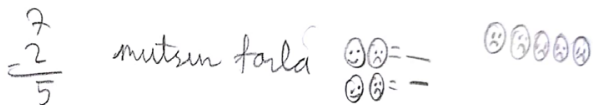

Așağıya bazı eşitikiker yazacağım. Bu soruya uygun bir eșitlik ya da eşitlikler varsa yuvarlak içine alır mısın? Niçin o eşitliği veya eşitlikleri seçtiğini açıklar mısın?
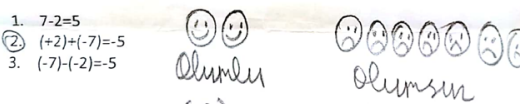

$(+2)$

$(-7)$

Figure 1. Ahu's answers for question 1

Another student, Engin, whose answers more closely aligned with Code 1 for both Part A and B, for example; "When she is sad for 7 times, so it goes to minus. When she is happy for 2 times, so it goes to 2 plus". The in-depth interviews conducted with students had revealed that those answers coded as Code 1 for parts A and B of the question had associated the positive and negative signs, for example, -7 and +2 with the emotions of happy and sad. In addition, as stated by one student, Ahu, it was recognized that the students who dealt with the relation of being happy and sad through the process of "elimination", complete the addition in the problem based on the cardinal values of the numbers.

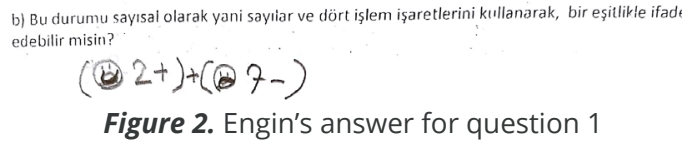

Review of the second question (question 2) was aimed at establishing a better understanding for the researchers of any relationship that may occur between the use of borrowing and negative numbers. The findings from question 2 are presented in Table 2 .

Table 2. The findings related to question 2

\begin{tabular}{lcc}
\hline & Part A & Part B \\
\hline Code 1 & 8 & 20 \\
\hline Code 2 & 82 & 76 \\
\hline Code 3 & 10 & 4 \\
\hline
\end{tabular}

It is important to point out that for Part A of the question 2 , a majority of the students ( $n=82)$, provided an answer relating to the question of borrowing 13 Turkish liras by using the operation of $5+8=13$. On the other hand, a very small amount of the students $(n=8)$ answered Part A of question 2 more related to Code 1, for example, writing the operation as $-8+-5=-13$. These responses were significant because it was clear that these students were able to associate negative numbers with the use of borrowing. As with the responses to the first question, the percentage of students who chose to write the operation for Part A of question 2 by utilizing negative numbers was quite low. For Part B of question 2, when specific mathematical expressions were provided to students, the number of students who answered the question more closely to Code 1 , increased from eight to 20 students, which was similar to what occurred in the first question. The result that these 20 students provided for the problem was $(-8)+(-5)=(-13)$. Importantly, when reviewing the codes for the other students answer responses, it was recognized that 76 of the students answered $8+5=13$ and four of them answered with $8-(-5)=13$. The four responses to the question which were $8-(-5)=13$ was actually an incorrect and irrelevant response to the problem.
Another student's responses to be discussed in detail were those of Sinan, who provided answers to both parts of question 2 in accordance with Code 1. Sinan's responses revealed that he believed the total debt could be determined when borrowing twice through the addition of two negative numbers. When the researchers inquired with $\mathrm{Si}$ nan why he utilized $(-8)+(-5)=(-13)$ as an equation for the answer, he stated; "Because -8 , I have borrowed 8 Turkish liras. In addition, plus 5 Turkish liras more I have borrowed, it means -5". When the researchers analysed all of the interviews conducted with the students, it was recognized that students whose answers for question 2 were related to Code 1 , had associated the debt case to negative numbers, as well as, the addition of two negative numbers to determine the total amount of the debt.

b. Bu durumu sayısal olarak veya eşitlikle ifade edebilir misin?

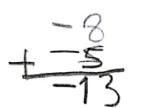

Aşaǧıva bazı eșitlikler yazacağım. Bu soruya uygun bir eşitlik ya da eşitlikler varsa yuvarlak içine alır mısın? Cevabını açıklar mısın?

1., $(-8)+(-5)=-13$

2. $8+5=13$

2. $8+5=13$

Figure 3. Sinan's answer for question 2

\section{Subtraction of integers}

In the third question (question 3 ) the researchers presented the students with a scenario of going down in an elevator below the ground floor and asked them to solve the question through subtraction. The question provided to the students was;

"5 floors of a 20 story building are underground, and 15 floors are above the ground. The entrance floor is assumed to be 0 . How many floors would the elevator go down if it went to the $3^{\text {rd }}$ floor underground from the $7^{\text {th }}$ floor? How do you show your result through an operation?"

Unlike the first two questions, there was no Part B for question 3 but the answers provided by the students were evaluated following the same coding system as question 1 . The analysis findings from the coding of the students answers for question 3 are provided in Table 3.

Table 3. The findings related to question 3

\begin{tabular}{cc}
\hline & Number of students \\
\hline Code 1 & 3 \\
\hline Code 2 & 53 \\
\hline Code 3 & 44 \\
\hline
\end{tabular}

When the researchers reviewed the students' answers from question 3 they recognized that slightly more than half of the students $(n=56)$ provided answers which were coded as Code 1 and Code 2, and that these students reached the correct solution for the questions through various strategies (e.g., counting the floors one-by-one, completing the operation, or counting through drawing). The results revealed that only three students coded as Code 1 provided the response $7-(-3)=10$ by using the logic of subtraction and negative numbers. In addition, just under half of the students $(n=44)$ that were coded as Code 3 provided incorrect and irrelevant answers. It appeared by the high number of incorrect responses that the students were challenged by a subtraction question, and as a result, the difficulty of the question seemed to reduce the students' level of interest in answering question 3. 
Among the responses there were three students who responded correctly but could not be reached for interviewing. These three students had provided the correct solution using the numbers 7 and -3 , and subtracting them in the answers but because they could not be contacted their motivation could not be investigated.

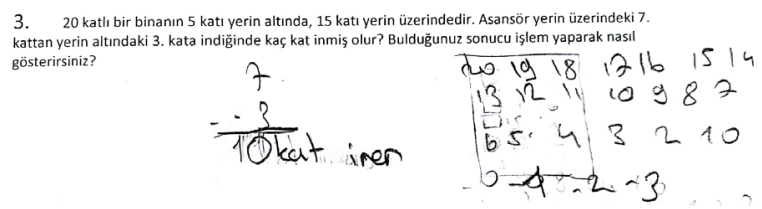

Figure 4. One of the correct answers for question 3

Less-than, greater-than relation

In the next question, question 4 , the researchers provided various pairs of numbers to the students and asked them to choose the number which was greater for each pair or put an equals sign, "=", if the numbers were equal. When analysing question 4 the researchers utilized the following coding system, and the analysis results are presented in Table 4.

Code 1: The correct answer was marked

Code 2: The incorrect answer was marked

Code 3: No answer marked

Table 4. The findings related to question 4

\begin{tabular}{lccc}
\hline \multirow{2}{*}{ Number pairs } & \multicolumn{3}{c}{ Students' Answers } \\
\cline { 2 - 4 } & Code 1 & Code 2 & Code 3 \\
\hline 3 and -7 & 85 & 11 & 4 \\
\hline 0 and -9 & 85 & 11 & 4 \\
\hline-5 and -6 & 66 & 29 & 5 \\
\hline-100 and -5 & 70 & 24 & 6 \\
\hline-3 and -3 & 89 & 4 & 7 \\
\hline
\end{tabular}

The analysis of the students' responses from question 4 revealed that when comparing positive and negative numbers or comparing 0 to negative numbers that a large majority of the students $(n=85)$ responded to the question correctly. While this ratio decreased somewhat for the questions ranking negative numbers (e.g., -5 and $-6,-100$ and -5 ) still a majority of the students, 66 in one case and 70 in another, correctly chose the greater number among two negative numbers. These findings revealed that the students had an intuitive understanding of negative numbers and could establish the relation between less-than and greater-than among integers. Furthermore, a high number of the students $(n=89)$ answered the question involving two equal negative numbers correctly.

The in-depth review of students' answers revealed that several students had a variety of motivations for providing the answer responses which they provided. For example, Deniz, correctly chose the greater number from a pair of a positive and a negative number, and according to Deniz the ordering of numbers among integers is similar to ordering the degrees of a thermometer;

"If we think of them as a degree, then negative numbers come below 0 . After that, even if we pass to normal numbers, the number 3 is greater than -7."

In addition, other students provided unique answers, for example, Ahu compared 0 and -9 and correctly answered that 0 is greater than -9 stating;

"Because it is a number with minus and it is somewhere below."
Similar to Deniz, the response from Ahu revealed she preferred to establish an ordinal relationship between numbers in the vertical direction. Another student, Ezgi, responded correctly by determining which negative number of the pair was greater, -5 or -6 . Ezgi did so by positioning the negative numbers relative to 0 and then determining;

"The -5 is greater because it is closer to 0. Zero is greater, too."

By providing an analogy related to an elevator going up and down, a student Emre, stated that his answer;

"Well, for example, when you put them in order, the lesser numbers are greater than the negative numbers. For example, let's think of something like an elevator in a building. Minus, a few minus goes down quite a bit."

While conducting the in-depth interview process regarding students motivations for the answers they provided, the researchers were taken by the comments from several students when they characterized positive numbers as "normal numbers", for example, Yağmur justified her characterization of the relation between less-than and greater-than numbers by expressing;

"Because -7 is already in the numbers with minus, 3 [is greater] because it is in the normal numbers" and "0 is a normal number in the same way but -9 is in the numbers with minus again".

The student, Ahu, also responded with correct answers when determining the negative number which was greater-than in the number pair, and provided a description of negative numbers as "decreasing numbers" by expressing;

"Normally, 5 is less than 6, but in these decreasing numbers, 1 and 9, -1 and -9. -1 is greater than [-9]".

The review of the interviews with the selected students revealed that among the students there was an understanding that positive numbers were "normal numbers" and that negative number were considered to be "minus or decreasing numbers".

\section{Ordering}

In the fifth question, (question 5), the researchers queried the students regarding the completion of a number line task where a number line was provided to students with spaces for both positive and negative numbers. In this task the only cues provided to students were the numbers +2 and +3 written in their places on the number line, and students were asked to complete the empty spaces on the number line including further positive numbers, zero, and the necessary negative numbers. The analysis of question 5 was completed by the researchers using the following coding system, and the analysis for the fifth question is presented in Table 5.

Code 1: The correct ordering was made

Code 2: The correct ordering was made but 0 was forgotten

Code 3: The positive numbers were correctly ordered but the

negative numbers were ordered in reverse

Code 4: Only the positive numbers were ordered

Code 5: All orderings were done incorrectly

Table 5: Findings of the question 5

\begin{tabular}{cccccc}
\hline $\begin{array}{c}\text { Given } \\
\text { Answers }\end{array}$ & Code 1 & Code 2 & Code 3 & Code 4 & Code 5 \\
\hline $\begin{array}{c}\text { Number } \\
\text { of }\end{array}$ & 53 & 10 & 14 & 12 & 11 \\
\hline
\end{tabular}

When review of question 5 was complete it was revealed that just over half of the students, $(n=53)$, had responded to the number line task correctly and were coded as Code 1. An 
example of a correctly completed number line task coded as Code 1 is provided in Figure 5. In addition, when reviewing the answers an additional 10 students were able to correctly order the integers on the number line but forgot to include the number 0 , and as a result, they were coded as Code 2. Another 26 of the students responded to the number line task by ordering the numbers based on the logic of positive numbers and these students were coded as either Code 3 (see Figure 6) or Code 4.

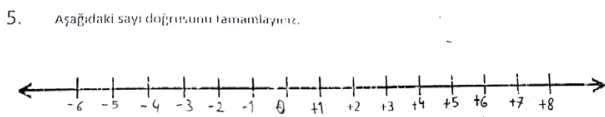

Figure 5. A Code 1 answer

5. Aşağı̀daki sayı doğrusunu tamamlayını.

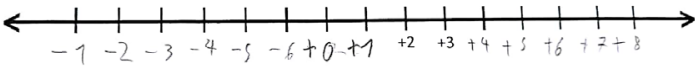

Figure 6. A Code 3 answer

When the researchers discussed the responses for question 5 with students whose answers were coded as Code 1 , it was recognized that these students were conscious that they were ordering the numbers correctly and they were doing so according to smaller to bigger relationship. For example, one of the students Harun stated that they began the ordering task at +2 and then ordered the numbers as follows;

"Here are the plus ones on this side, I went back +1 , subtracting one number like +1 [then] 0 . Then I went backwards through minus numbers."

When the students who had responded to question 5 correctly were further queried about their answers, and in particular, if they had prior knowledge regarding their ordering choices; most stated not learning about ordering in class but instead completed the question based on the ordering they had witnessed in the thermometer and elevator scenarios. Only one student, Ahu, had stated that she had been exposed to negative numbers in school through the prize-penalty activity from kindergarten. The explanation from Ahu was that stars could be earned for good behaviour and stars could be lost for bad behaviour. This past prize-penalty activity made her realize that there must be numbers less than zero. Ahu's statements went as follows;

"We had such a lesson when we were in kindergarten, so if when we did bad then we got minus; it means our stars would decrease. When we did something good, our stars would in crease. A friend of ours was out of stars, but after that a minus 2 was written on board. Minus 2, that is, if there were 2 more stars, she would also lose them, so I remembered it from kindergarten."

Through Ahu's statements the researchers were able to understand that she had used the star analogy to make a cardinal relation between the positive and negative numbers, and as a result, she could transform her ideas into an ordinal number relationship when answering the test question.

\section{Conclusion}

The goal of this research was to investigate the intuitive understanding of the concept of integers among primary school students, and in particular, to gain a clearer understanding of how the students utilized their intuitive knowledge to answer specific questions related to positive and negative integers. In order to reveal if the students participating in this study had an intuitive sense of integers as well as how they utilized their intuitive knowledge to an- swer integer related questions, the students were assessed through a variety of integer concepts. The researchers first assessed the students regarding a variety of integer concepts including; integer ordering, less-than greater-than relations, and integer addition and subtraction. Following the assessment process, the researchers' analysis of the students' answers revealed that a majority of the students had considerable intuitive knowledge regarding the ordering and less-than, greater-than relationships of integers. For example, many of the students appeared to be aware of negative numbers, could correctly distinguish between positive and negative numbers, and also determine the greater number between a pair of disparate numbers. In addition, to better understand how students utilized their intuitive knowledge to answer the assessment questions, the researchers conducted in-depth semi-structured interviews with a small select group of students.

To begin, the in-depth interviews between the researchers and the select group of students revealed that students often made their decisions based on the concept of ordinality. This finding was important because Bofferding (2014), had also determined that young children can perceive numbers as being positional (ordinal). In addition, the assessment results revealed that a vast majority of the students were able to place negative numbers on an empty number line, as well as, establish ordering relations among integers including negative integers less than zero. These findings were also significant because similar findings had been revealed in other past studies with primary school students (Bishop et al., 2011, 2014; Hativa \& Cohen, 1995; Wilcox, 2008). In the interviews with students, researchers also queried the students regarding how they ordered the integers for the number line task, and the students' responses revealed that they had utilized both the concepts of cardinality and ordinality for completing the number line task.

Another remarkable finding that was revealed by this study regarded the students' ability to carry out integer assessment addition tasks. Although a greater number of the students reached the correct answer by using positive numbers, the research findings also revealed that some students correctly answered the questions utilizing negative numbers. When considering the use of positive numbers it was recognized that in question 2, a total of 60 out of 100 students achieved their answers by way of positive numbers. These students had answered questions regarding debt by considering how much they owed through positive numbers and not by considering the use of negative numbers. This finding was also interesting because Whitacre, Bishop, Lamp, Philipp, Schappelle \& Lewis' (2012b) had previously uncovered similar results in their study.

Continued review of the research analysis revealed that a small number of students, on question $1(n=20)$ and question $2(n=26)$, were able to utilize negative numbers in solving the questions, as well as, include negative numbers when completing the addition questions. Also, because of the scenarios presented to the students, it was recognized that they were able to consciously associate both positive and/or negative numbers with the idea of being happy or sad, as well as, with the idea of being in debt. For example, students had commented during the in-depth interviews that in question 1 they had added a negative number to a positive number through elimination, and for question 2 they stated associating the sum of two negative numbers with the total amount of debt. Importantly, the review of the students' responses showed that for both questions related to addition, the students had considered the cardinal values of the associated numbers. This finding was similar to Whitacre et al., (2012a), where it had been determined that children in younger age groups are in fact able to associate contrasting situations to integers. 
As mentioned previously, the researchers had presented the students with scenario questions in their pursuit of better understanding the students' intuitive understanding of the concept of integers as well as negative numbers. For question 3, a subtraction question was presented through the scenario of an elevator going up and down between positive and negative floors of a building. The research findings for question 3 revealed that very few students $(n=3)$ provided a correct response by utilizing negative numbers. While on the other hand, over half of the students $(n=53)$ responded correctly to question but did so by utilizing a variety of methods. In general, the students appeared to find their solutions for question 3 by merely drawing models as well as counting the floors one-by-one.

In this study, the intuitive understanding of primary school students was investigated without the aid of an instructional experiment, and after review of the research findings it was revealed that the young students have developed an intuitive understanding of integers without prior exposure to the concept of integers from formal instruction and learning. The findings of this study are supported by several relevant studies from past research literature (Bishop et al., 2011; Bishop et al., 2014; Wilcox, 2008; Whitacre et al., 2012a). The intuitive understanding of integers that the students in this study exhibited should be considered the prior knowledge that underpins their future integer learning. The results of this research make it clear that throughout their daily lives, young children are constantly exposed to negative and positive numbers, and that these encounters are based both on the ordinal and cardinal meanings of numbers. Also, while many students understand the idea of borrowing through the cardinal value of numbers, they can also establish the relationship of ordering in integers when they are exposed to everyday items such as elevators and/or thermometers.

The findings of this research also highlight the point that while students have developed an intuitive understanding of integers during primary school, in most cases, the formal instruction of integers does not begin until the $6^{\text {th }}$ grade which could be delaying young students' further understanding and learning of the concept of integers. Other important considerations are also warranted, for example, according to Fischbein (1987); Linchevski and Williams (1999), it has been recognized that the preliminary learning of natural numbers can negatively affect the learning of integers. In addition, Fischbein (1987), also attributed the difficulty experienced by students to the contradiction between the concepts, "quantity" and "magnitude", as they are related to natural numbers as well as to students attempts to transfer the usage of these concepts to negative numbers. In order to counteract these misconceptions among young students it can be argued that integers should be taught at an earlier age as an extension of positive numbers. An example of this idea was posited by Hativa and Cohen (1995), when they stated that an early introduction of students to the concept of negative numbers as well as some features related to integers can ultimately prevent students future learning difficulties associated to the concept of integers.

Considering the findings from this research study along with the findings from other past studies, it appears that the instruction of negative numbers to children before the secondary school level, should not only be carried out but in a manner that builds upon the children's intuitive understanding of these concepts. In addition, children's intuitive understanding of concepts and their ability to learn intuitively should also be supported in the students' formal education. In order to take advantage of students' intuitive learning, it is important to provide a variety of examples from daily life when teaching integers, and as a result, expose students to positive and negative numbers based on real life experiences, as well as, through the use of the concepts of cardinality and ordinality.

For future research, it is important to recognize that this study only investigated the intuitive understanding of the concept of integers and negative numbers among $4^{\text {th }}$ grade students. As a result, new research studies regarding the intuitive understanding and instruction of integers to students should consider focusing on children in the earlier grades of primary school. The question of how to configure the instruction of integers before the $6^{\text {th }}$ grade in effect remains unanswered, so it is suggested that this study and it findings be combined with future studies regarding the process of integer instruction for younger age children. This synthesis of research can be done in order to gain a better understanding of the relationship between students' intuitive and formal learning abilities, and in the end utilize the gathered information to develop future curriculum for young students that takes advantage of their manner of learning and understanding.

\section{References}

Altiparmak, K. \& Özdoğan, E. (2010). A study on the teaching of the concept of negative numbers. International Journal of Mathematical Education in Science and Technology, 41(1), 31-47.

Altun, M. (2008). ilkögretim Ikinci Kademe (6, 7 ve 8. sınıflarda) Matematik Öğretimi (6. Baskı), Bursa: Aktüel Yayınları.

Ball, D. L. (1993). With an eye on the mathematical horizon: Dilemmas of teaching elementary school mathematics. The Elementary School Journal, 93(4), 373-397.

Behrend, J. L., \& Mohs, L. C. (2006). From simple questions to powerful connections: A two-year conversation about negative numbers. Teaching Children Mathematics, 12(5), 260-264.

Beswick, K. (2011). Positives experiences with negative numbers: Building on students' in and out of school experiences. Australian Mathematics Teachers, 67(2), 31-40.

Bishop, J. P., Lamb, L. L. C., Philipp, R. A., Schapelle, B. P., \& Whitacre, I. (2011). First graders outwit a famous mathematician. Teaching Children Mathematics, 17(6), 350-358.

Bishop, J., Lamb, L., Philipp, R., Whitacre, I., \& Schappelle, B. (2014). Using order to reason about negative numbers: The case of Violet. Educational Studies in Mathematics, 86(1), 39-59.

Bofferding, L. (2014). Negative integer understanding: Characterizing first graders' mental models. Journal for Research in Mathematics Education, 45(2), 194-245.

Büyüköztürk, Ş., Çakmak, E. K., Akgün, Ö. E., Karadeniz, Ş., \& Demirel, F. (2012). Bilimsel Araştırma Yöntemleri. Pegem A.

Carson, C. L., \& Day, J. (1995). Annual report on promising practices: How the algebra project eliminates the game of signs" with negative numbers. San Francisco, CA: Far West Lab for Educational Research and Development.

Cathcart, W. G., Pothier, Y. M., Vance, J. H., \& Bezuk, N. S. (2003). Learning Mathematics in Elementary and Middle Schools (Third Edition). Upper Saddle River, NJ: Prentice. 
Crowley, M. L., \& Dunn, K. A. (1985). On multiplying negative numbers. The Mathematics Teacher, 78(4), 252-256.

Fischbein, H. (1987). Intuition in Science and Mathematics: An Educational Approach. Dordrecht, The Netherlands: Reidel.

Galbraith, M. J. (1974). Negative numbers. International Journal of Mathematical Education in Science and Technology, 5 (1), 83-90.

Gelman, R., \& Gallistel, C. R. (1986). The Child's of Number. Cambridge: Harvard University Press.

Goldin, G., \& Shteingold, N. (2001). Systems of representations and the development of mathematical concepts. The Roles of Representation in School Mathematics, NCTM, Reston, VA, 1-23.

Hativa, N., \& Cohen, D. (1995). Self-learning of negative number concepts by lower division elementary students through solving computer-provided numerical problems. Educational Studies in Mathematics, 28(4), 401-431.

Işıksal Bostan, M. (2009). Negatif sayılara ilişkin zorluklar, kavram yanılgıları ve bu yanılgıların giderilmesine yönelik öneriler. Illköğretimde Karşılaşılan Matematiksel Zorluklar ve Çözüm Önerileri, Ankara: Pegem Akademi Yayınları, 155-183.

Kilpatrick, J., Swafford, J., \& Findell, B. (2001). Adding it up: Helping children learn mathematics (National Research Council. Mathematics Learning Study Committee). Washington: National Academy Press.

Kümbetoğlu, B. (2008). Sosyolojide ve Antropolojide Niteliksel Yöntem ve Araştırma. İstanbul: Bağlam Yayıncılık.

Linchevski, L. \& Williams, J. (1999). Using intuition from everyday life in 'filling' the gap in children's extension of their number concept to include the negative numbers. Educational Studies in Mathematics, 39(1) 131-147.

Milli Eğitim Bakanlığı. (2013). Ortaokul Matematik Dersi (5, 6, 7, 8. sınıflar) Öğretim Programı [Secondary school mathematics curriculum]. Ankara: Talim ve Terbiye Kurulu Başkanlığı.

Milli Eğitim Bakanlığı. (2017). Matematik Dersi Öğretim Programı [Mathematics curriculum]. Ankara: MEB.

Murray, J. C. (1985). Children's informal conceptions of integer arithmetic. In Proceedings of The Ninth International Conference for the Psychology of Mathematics Education (Vol. 1), Utrecht, the Netherlands: The State University of Utrecht, 147-155.

National Council of Teachers of Mathematics (1989). Curriculum and Evaluation Standards for School Mathematics. Washington, DC: Author.

National Council of Teachers of Mathematics (2000). Principles and Standards for School Mathematics. Reston, VA: Author.

Otten, S. (2009). Down and to the left: Students' movement toward negative numbers. Michigan State University, Retrieved from: https://msu.edu/ ottensam/ SME840_Otten_paper1.pdf .

Streefland, L. (1996). Negative numbers: Reflections of a learning researcher. The Journal of Mathematical Behavior, 15(1), 57-77.
Van de Walle, J. A., Karp, K. S., \& Williams, J. M. B. (2007). Elementary and Middle School Mathematics: Teaching Development. Boston: Pearson.

Vlassis, J. (2008). The role of mathematical symbols in the development of number conceptualization: The case of the minus sign. Philosophical Psychology, 21(4), 555-570.

Whitacre, I., Bishop, J., Lamb, L., Phillipp, R., Schappelle, B. P., \& Lewis, M. (2012a). Happy and sad thoughts: An exploration of children's integer reasoning. Journal of Mathematical Behavior, 31(3), 356-365.

Whitacre, I., Bishop, J., Lamb, L., Philipp, R, Schappelle, B. P., \& Lewis, M. (2012b). What sense do children make of negative dollars? In L. Van Zoest, J. Lo., \& J. Kratky (Eds.), Proceeding of the $34^{\text {th }}$ Annual Meeting of the North American Chapter of the International Group for the Psychology of Mathematics Education, Kalamazoo, Ml: Western Michigan University, 958-964.

Wilcox, V. B. (2008). Questioning zero and negative numbers. Teaching Children Mathematics, 15(4), 202-206. 